\title{
Pregnancy Outcome in Mothers Over the Age of 35
}

DOI:

10.1097/GCO.0000000000000494

\section{Document Version}

Accepted author manuscript

Link to publication record in Manchester Research Explorer

\section{Citation for published version (APA):}

Heazell, A., Newman, L., Lean, S., \& Jones, R. (2018). Pregnancy Outcome in Mothers Over the Age of 35. Current opinion in obstetrics \& gynecology, 30(6), 337-343. https://doi.org/10.1097/GCO.0000000000000494

\section{Published in:}

Current opinion in obstetrics \& gynecology

\section{Citing this paper}

Please note that where the full-text provided on Manchester Research Explorer is the Author Accepted Manuscript or Proof version this may differ from the final Published version. If citing, it is advised that you check and use the publisher's definitive version.

\section{General rights}

Copyright and moral rights for the publications made accessible in the Research Explorer are retained by the authors and/or other copyright owners and it is a condition of accessing publications that users recognise and abide by the legal requirements associated with these rights.

\section{Takedown policy}

If you believe that this document breaches copyright please refer to the University of Manchester's Takedown Procedures [http://man.ac.uk/04Y6Bo] or contact uml.scholarlycommunications@manchester.ac.uk providing relevant details, so we can investigate your claim.

\section{OPEN ACCESS}




\section{Current Opinion in Obstetrics and Gynecology \\ Pregnancy Outcome in Mothers Over the Age of 35 \\ --Manuscript Draft--}

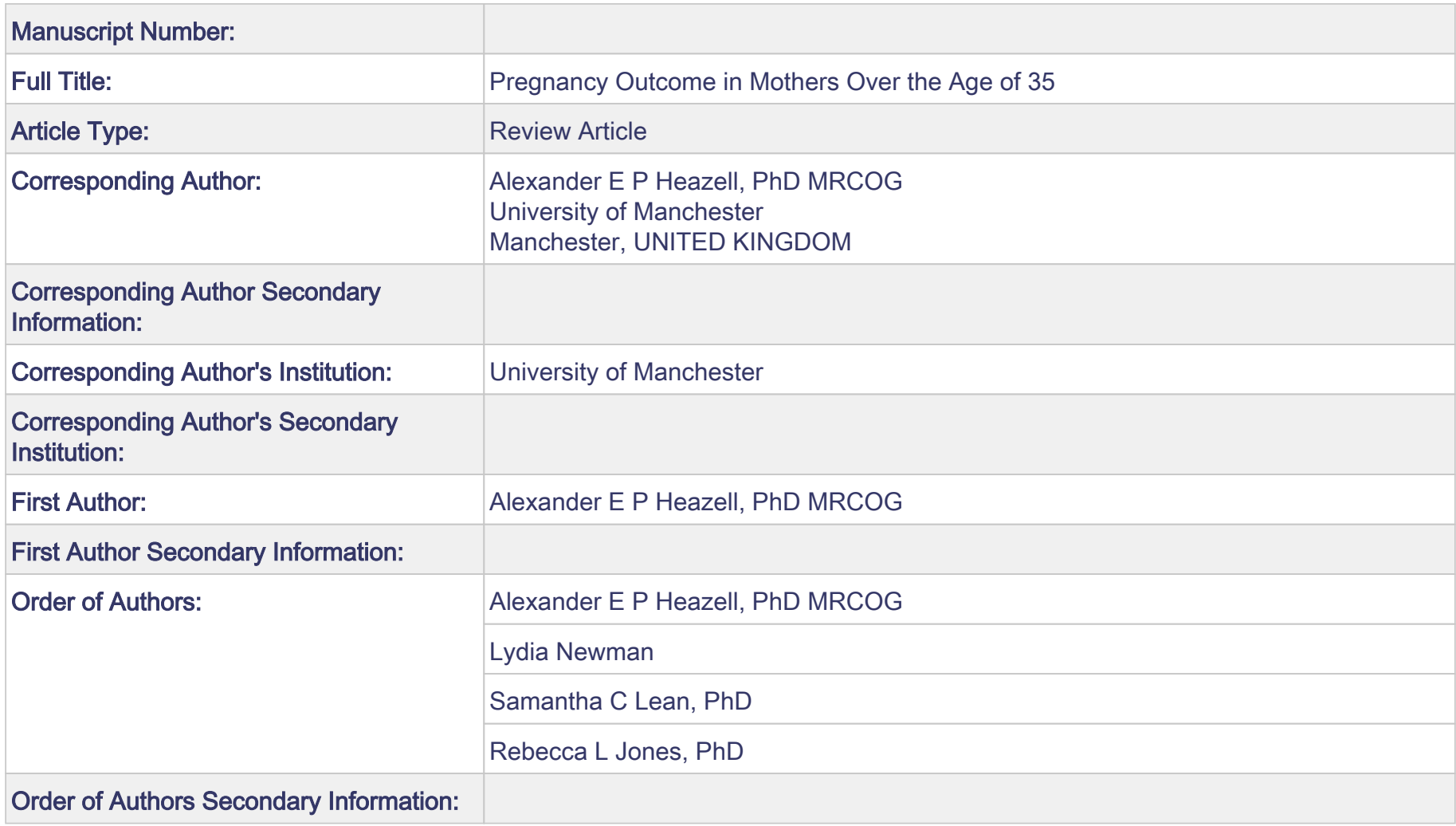




\section{Pregnancy Outcome in Mothers Over the Age of 35}

Alexander E P Heazell, Lydia Newman, Samantha Lean, Rebecca L Jones.

Maternal and Fetal Health Research Centre, Division of Developmental Biology and Medicine, School

of Medical Sciences, Faculty of Biology Medicine and Health, St Mary's Hospital, Oxford Road, M13

9WL, University of Manchester, UK

Corresponding Author - Professor Alexander Heazell

Maternal and Fetal Health Research Centre, 5th floor (Research), St Mary's Hospital, Oxford Road, Manchester, M13 9WL, UK

Email-alexander.heazell@manchester.ac.uk 


\begin{abstract}
Purpose of review - The proportion of pregnancies occurring in women $\geq 35$ years of age has increased from $6.2 \%$ in 1980 to $22.3 \%$ of births in 2016. This review summarises recent epidemiological and basic scientific studies investigating the association between older maternal age and adverse pregnancy outcome(s) and clinical studies which investigate the effects of intervention to reduce adverse events.
\end{abstract}

Recent findings - Women $\geq 35$ years of age have increased risk of maternal and fetal complications in pregnancy including: stillbirth, a small for gestational age baby, preterm birth, pre-eclampsia and maternal death. These risks increase with increasing age. The reasons for this increased risk are incompletely understood, but likely involve ageing of the maternal cardiovascular and endocrine systems which impacts upon placental function. Intervention, by induction of labour (IOL) at 39 weeks gestation does not increase operative deliveries or short-term adverse maternal and neonatal otucomes and would reduce perinatal mortality.

Summary - The additional risks of pregnancy should be discussed with women $\geq 35$ years of age; additional fetal surveillance may be required in the antenatal period. The benefits and risks of IOL at 39 weeks' gestation should be discussed with women $\geq 35$ years of age.

\title{
Keywords
}

Advanced maternal age; Stillbirth; Perinatal mortality; Induction of labour. 


\section{Introduction}

In the UK there has been a focus on reducing the number of stillbirths, neonatal deaths, maternal deaths and brain injuries occurring at or soon after birth, with a specific aim to reduce these adverse events by half by 2025 . Although the origins of these events are complex and multifactorial there is overlap between risk factors which are associated with these adverse outcomes. One maternal factor which is associated with adverse outcomes for infants and mothers is maternal age. Although the definition of advanced maternal age (AMA) varies, it is widely defined as maternal age $>35$ years of age (1). Epidemiological studies, the most recent of which will be reviewed in this article, have described an association between maternal age $\geq 35$ years of age and fetal and maternal mortality and morbidity. This relationship is of particular importance because the proportion of pregnancies occurring in this group of women in the UK has increased steadily from $6.2 \%$ in 1980 to $22.3 \%$ of births in 2016 (Figure 1) (2). This trend has been replicated in many high-income countries including those in Western Europe, North America and Australia (3-6). The reasons for the change towards delayed childbearing are complex and beyond the scope of this review, but include the availability of safe, effective contraception, access to education and career and to be in a stable relationship with a supportive partner. More prevalent use of artificial reproductive techniques (ART) may also account for a proportion of the increase in births in this age group (7). This review will summarise recent scientific, observational and interventional clinical studies which explore the association between AMA and adverse outcomes and consider how this risk can be reduced.

\section{Relationship between AMA and adverse fetal outcomes}

There have been a large number of studies which have explored the relationship between maternal age and adverse fetal outcomes. A meta-analysis of observational studies performed in 2017 included 63 cohort studies and 12 case-control studies (8). The primary outcome of interest was stillbirth; the meta-analysis included 44 studies reporting the outcome of 44,723,207 births, including 185,234 stillbirths. This found that the pooled odds ratio (OR) for stillbirth for women $\geq 35$ 
years of age was 1.76 (95\% Confidence Interval (95\% Cl 1.63-1.90); meta-regression identified that Critically, there was no difference in this relationship between geographical location or the year of study. There was significant heterogeneity between estimates of the effect size between studies, suggesting that other factors may mediate some of the increased risk of stillbirth. Due to its size, this systematic review also explored the relationship between factors which could account for the increased risk of stillbirth in women $\geq 35$ years; these included maternal co-morbidities (e.g. obesity, diabetes, hypertension) and the use of ART. Only maternal hypertension was correlated with stillbirth in women over the age of 35 , suggesting that maternal age is an independent risk factor for stillbirth (8).

Although this meta-analysis was able to provide clear evidence of the association between stillbirth and maternal age $\geq 35$ years, it was not able to determine the origins of this increased risk. Earlier studies identified that stillbirths in women over the age of 35 more frequently occur in late pregnancy, with an apparent shift in the increased stillbirth rate seen at 41 weeks in younger women (1 in 1333) to 40 weeks in women $\geq 35$ years of age ( 1 in 735) (9). A study of 637 stillbirths occurring in women over the age of 35 found that in this population stillbirths were more commonly due to major congenital anomalies (relative risk ratio (RRR) 2.0, 95\% Cl 1.3-3.0), mechanical causes (RRR 1.6), maternal disorders (RRR 2.1, 95\% Cl 1.2-3.6), and associated obstetric factors (RRR $2.1,95 \% \mathrm{Cl}$ 1.1-3.9) (10). Unfortunately, this study employed the classification system employed by Centre for Maternal and Child Enquiries (CMACE), using which results in a high proportion of deaths (29\%) with no relevant factors identified, in part because this classification system had no means to record fetal growth restriction (FGR) or placental pathology as a cause for stillbirth, both of which are important risk factors. The association of maternal age $\geq 35$ years with conditions which are strongly associated with placental disorders, such as small for gestational age (SGA) infants and pre-eclampsia, raises the possibility that AMA could be associated with increased risk of stillbirth by placental dysfunction. 
The relationship between maternal age $\geq 35$ years and other adverse fetal outcomes was also outcomes. Meta-analysis defined an increased risk of SGA (OR 1.16, 95\% Cl 1.06-1.27; 25 studies of $16,949,750$ births), low birth weight $<2500$ g (OR 1.37, 95\% Cl 1.26-1.50; 35 studies of 18,360,387 births), preterm birth (<37 weeks' gestation, OR 1.45, 95\% Cl 1.38-1.53; 46 studies of 24,551,442 births), neonatal death (OR 1.48, 95\% Cl 1.30-1.67; 27 studies of 13,245,799 births) and admission to neonatal intensive care unit (OR 1.49, 95\% Cl 1.34-1.66; 20 studies of 645,661 births) in women $\geq 35$ years (8). In general the risk of adverse outcomes increased in women aged over 40 years and was highest in women over 45 years of age, suggesting risk increases with advancing age $(8,11)$. As this meta-analysis pooled data from observational studies, it is possible AMA is linked to adverse fetal outcome(s) by confounding factors which were not measured by this analysis. Interestingly, women over the age of 35 are more likely to have higher levels of education, higher income, and are more likely to be employed and attend prenatal classes, all of which reduce the risk of adverse pregnancy outcomes $(12,13)$. Thus, despite these favourable characteristics, AMA still appears to be an independent risk factor for adverse fetal outcome(s).

\section{Relationship between AMA and adverse maternal outcomes}

The relationship between maternal age and maternal mortality has been explored in international studies, which demonstrate a non-linear increase in the maternal mortality ratio with maternal age, with the highest maternal mortality rates in women in the oldest age groups $(14,15)$. A UK case control study of 105 maternal deaths identified factors which were significantly associated with maternal deaths in women $\geq 35$ years compared to those $<35$ years of age; these were: cigarette smoking during pregnancy (adjusted $\mathrm{OR}(\mathrm{aOR}) 2.1,95 \% \mathrm{Cl} 1.1-3.8$ ), inadequate use of antenatal care (aOR 23.6, 95\% Cl 8.8-63.5), medical co-morbidities (aOR 5.9, 95\% $\mathrm{Cl} 3.6-9.9$ ) and previous pregnancy complications (aOR 2.1, 95\% Cl 1.2-3.5) (16). In this study the odds of maternal death increased by $12 \%$ per year increase in age. Co-morbidities that were highlighted in cases of maternal 
death were cardiac disease, hypertension, infection, musculoskeletal disorders, asthma, mental health disorders and neurological diseases (16). Importantly, the greater number of risk factors for maternal mortality that were present, the greater the risk of maternal mortality ( 1 risk factor OR 2.8, 95\% $\mathrm{Cl}$ 1.4-5.4, 3 risk factors OR $26.1,95 \% \mathrm{Cl}$ 10.9-62.3). This study highlighted the importance of high-quality antenatal care for women over the age of 35 , particularly those with medical comorbidities. In their systematic review and meta-analysis Lean et al. described an association between maternal complications of pregnancy and maternal age $\geq 35$ including pre-eclampsia (OR 2.0, $95 \% \mathrm{Cl} 1.6-2.4 ; 38$ studies of 10,230,730 births), placental abruption (OR 1.5, 95\% Cl 1.4-1.7; 32 studies of $8,843,049$ births) and gestational diabetes (OR 2.8, 95\% Cl 2.5-3.3; 28 studies of 1,694,232 births) (8). These findings suggest that medical co-morbidities, particularly those affecting the maternal cardiovascular and endocrine systems, may mediate some of the effects of age on maternal morbidity and mortality.

\section{Evidence from basic science studies of AMA}

In addition to epidemiological studies, basic science investigations have been carried out to explore potential pathophysiological mechanisms underpinning the increased risk of adverse outcome in mothers $\geq 35$ years of age. Placentas from normal outcomes in women $\geq 35$ years have increased placental weight and decreased fetal:placental weight ratio compared to women aged 20-30 years (17). Fetal:placental weight ratio is decreased in SGA and FGR pregnancies, which is thought to result from increased placental size in an attempt to increase nutrient transfer to the fetus (18-20). At a microscopic level, trophoblast proliferation is reduced and the presence of syncytial nuclear aggregates (also termed syncytial knots) in increased (17). These changes are also seen in post-term pregnancies and in FGR stillbirths (21-23), thus these observations are consistent with a hypothesis of accelerated placental ageing in mothers $\geq 35$ years of age, which could explain the increased risk of stillbirth from 40 weeks' gestation seen at 42 weeks' gestation in women $<35$ years of age (9). Ageing is a complex process involving oxidative stress and inflammation. Preliminary data suggests 
that women $\geq 35$ years of age with normal pregnancy outcomes have increased total antioxidant cytokines (IFN- $\gamma$, TNF- $\alpha$, IL-8 and IL-1 $\alpha$ ) in their blood compared to women aged 20-30 years, whereas those mothers $\geq 35$ with adverse outcomes have increased evidence of oxidative stress and a further reduction in anti-inflammatory cytokines (24).

The effect of AMA has been explored in two animal models (mouse and rat). There are important similarities in pregnancy outcome in these models and pregnancy outcome in women $\geq 35$ years of age with increased fetal loss rate and high levels of FGR. Both rodent models of AMA had larger placentas and lower fetal:placental weight ratios $(17,25,26)$. There were also some changes in vascular behaviour with the mouse model showing increased endothelial-dependent relaxation in AMA and there was increased myogenic responses in systematic and uterine arteries in AMA rats $(17,26)$. AMA mice also showed reduced uterine artery remodelling during pregnancy compared to young controls (27). There was also reduced placental amino-acid transport in the AMA mouse model compared to young mice which indicates a reduction in placental efficiency (17). These findings support the human data, suggesting that abnormal placental function is evident in AMA. Further research is needed to determine the origins of the observed reduction of placental function, and whether it is amenable to therapeutic intervention.

\section{Intervention studies in mothers of AMA}

As women have an increased risk of adverse fetal and maternal outcome, particularly stillbirth in late pregnancy, consideration has been given to whether women $\geq 35$ years of age should have additional antenatal surveillance and earlier birth advised (28). The increased incidence of FGR has led to the recommendation that maternal age $\geq 40$ years should be considered an indication for regular assessment of fetal growth in late pregnancy and women aged $\geq 35$ years should have this in the presence of other risk factors for FGR (29). Consideration should also be given to screening for gestational diabetes and hypertensive disorders of pregnancy. Various studies report that earlier 
delivery is currently offered to women $\geq 35$ years $(30,31)$; a survey published in 2012 found that $37 \%$ of obstetricians offered induction of labour (IOL) at term to women aged $40-44$, rising to $55 \%$ for women aged $\geq 45(30)$. This practice raised concerns that this intervention could precipitate an increase in Caesarean section or instrumental vaginal births as women $\geq 35$ years of age have an increased risk of these procedures (32). In nulliparous women, there is a linear association between maternal age and birth by emergency Caesarean section (32). This concern was addressed by the 3539 trial, a randomised controlled trial of IOL at 39+0 - 39+6 weeks' gestation compared to expectant management. The primary outcome of this trial was Caesarean section, which did not differ between the two groups with $98 / 304$ in the induction group and 103/314 in the expectant management group (Relative risk $0.99,95 \% \mathrm{Cl} 0.87-1.14$ ) (33). There was also no difference in the incidence of the secondary outcomes (including: placental abruption, post-partum haemorrhage, Apgar score $<7$ at 5 minutes, admission to NICU) between groups. This trial concluded that IOL in women $\geq 35$ years of age at 39 weeks' gestation was not associated with a change in the rate of Caesarean section or adverse maternal or neonatal outcomes (33). A cost-utility analysis performed alongside the trial based upon quality of life measures and estimates of resource use found that IOL at 39 weeks was associated with a cost-saving of $f 263$ (34).

There were no stillbirths amongst participants of the 35-39 trial, which was unsurprising as there were 619 participants, and the trial was not statistically powered to investigate a change in stillbirth rate. However, the potential effect of $\mathrm{IOL}$ in nulliparous women $\geq 35$ years of age was compared to expectant management using routinely collected data from English hospitals between 2009-2014. This analysis of 77,327 women, $33 \%$ of whom had induction of labour, found IOL at 40 weeks' gestation was associated with a lower incidence of in hospital perinatal death compared to women who had expectant management $(0.08 \%$ vs. $0.26 \%$ (adjusted risk ratio aRR $0.33,95 \% \mathrm{Cl} 0.13-0.80$ ) and a lower risk of meconium aspiration syndrome ( $0.44 \%$ vs. $0.88 \%$, aRR $0.52,95 \% \mathrm{Cl} 0.35-0.78)$ (35). However, in this analysis there was increased risk of instrumental delivery (aRR $1.06,95 \% \mathrm{Cl}$ 1.01-1.11) and emergency Caesarean section (aRR 1.05, 95\% Cl 1.01-1.09). This study noted that 
there was a high number needed to treat to prevent one stillbirth, for women aged $\geq 35,562$ IOLs need to be performed to reduce one perinatal death (35).

\section{Conclusions}

Epidemiological data has demonstrated that women over the age of 35 have increased risk of adverse maternal and neonatal outcomes, with increasing risk with increasing age. It is uncertain whether all these risks are greater in nulliparous women, but the risk of adverse outcome appears greater when co-morbidities are present. The reasons for the increased risk of adverse outcomes are not completely understood and potentially include age-related changes in the maternal cardiovascular, immune and endocrine systems. The association with stillbirth, SGA infants, preeclampsia and placental abruption all suggest a placental component to adverse neonatal outcome which is supported by evidence from scientific studies. Consequently, women $\geq 35$ years of age should have risk-factors for adverse outcome assessed at booking and have ultrasound assessment of fetal growth in the third trimester if other risk factors for FGR are present and women $\geq 40$ should be offered aspirin 150mg once a day and regular assessment of fetal growth in the third trimester. The increased risk of stillbirth (even with a normally grown baby) should be discussed with mothers $\geq 35$ years of age and women should be offered IOL (unless vaginal birth is contraindicated) at 39 weeks gestation. There is now sufficient data from recently published trials and analyses to inform women about the number needed to treat and the likelihood that there is little effect on the incidence of vaginal birth. Importantly, women may interpret data differently as illustrated by the proportion of women (60.8\%) that declined to participate in the 35-39 study (33). However, unbiased information should be provided to women so they can make an informed decision. A policy of IOL in women over 35 years of age in a maternity unit of 5,000 births (of which 1,115 women would be $\geq 35$ ) would be expected to prevent approximately 2 perinatal deaths per year. Thus, this strategy would be unlikely to produce a significant reduction in stillbirth in isolation but would contribute to the goal of reducing stillbirth and neonatal death by $50 \%$ by 2025 . 


\section{Key points}

- Women over the age of 35 have increased risk of a range of adverse maternal and neonatal outcomes following pregnancy, including stillbirth and maternal death.

- The risk of adverse outcomes increases with maternal age and interacts with other risk factors e.g. medical co-morbidities to further increase the risk for women and their babies.

- Intervention by induction of labour at 39 weeks' gestation is not associated with increased risk of Caesarean section, is economically sustainable and would reduce perinatal mortality.

\section{Financial support and sponsorship}

This work and the Manchester Advanced Maternal Age Study was financially supported by Tommy's, UK.

\section{Conflict of Interest Statement}

There are no conflicts of interest associated with any of the authors involved in this work. 


\section{References}

1. Laopaiboon M, Lumbiganon P, Intarut N, Mori R, Ganchimeg T, Vogel JP, et al. Advanced maternal age and pregnancy outcomes: a multicountry assessment. BJOG. 2014;121 Suppl 1:49-56.

2. Office of National Statistics. Births by Parents' Characteristics 1938-2016. London: Office of National Statistics, 2018.

3. Botting B, Dunnell K. Trends in fertility and contraception in the last quarter of the 20th century. Popul Trends. 2000(100):32-9.

4. Atlas of Health in Europe, 2nd edition, 2008, World Health Organization, Geneva.

5. Birth Statistics 2005-2016. 2018, Australian Bureau of Statistics, ACT, Australia.

6. Martin JA, Hamilton BE, Osterman MJK, Driscoll AK, Matthews TJ. National Vital Statistics Reports, Births: Final Data for 2015. 2017, U.S. Department of Health and Human Services, Hyattsville, MD, USA.

7. Shea LO, Hughes C, Mocanu EV. Advanced Maternal Age and Assisted Reproductive Technologies in an Irish Population. Ir Med J. 2015;108(8):243-6.

** 8. Lean SC, Derricott $\mathrm{H}$, Jones RL, Heazell AEP. Advanced maternal age and adverse pregnancy outcomes: A systematic review and meta-analysis. PloS one. 2017;12(10):e0186287. A large metaanalysis of observational studies describing association between maternal age and adverse neonatal and maternal outcomes. This study found an increasing incidence of stillbirth with increasing maternal age, which was independent of maternal co-morbidites and the use of assisted reproductive technologies.

* 9. Reddy UM, Ko CW, Willinger M. Maternal age and the risk of stillbirth throughout pregnancy in the United States. Am J Obstet Gynecol. 2006;195(3):764-70. This study specifically analysed the risk of stillbirth at specific gestation for women of different ages; this analysis showed that the 
stillbirth rate in women $\geq 35$ years of age increases after 39 weeks gestation to levels greater than $<35$ years at $>41$ weeks gestation.

10. Walker KF, Bradshaw L, Bugg GJ, Thornton JG. Causes of antepartum stillbirth in women of advanced maternal age. Eur J Obstet Gynecol Reprod Biol. 2016;197:86-90.

11. Fitzpatrick KE, Tuffnell D, Kurinczuk JJ, Knight M. Pregnancy at very advanced maternal age: a UK population-based cohort study. BJOG. 2017;124(7):1097-106.

12. Bayrampour $\mathrm{H}$, Heaman M. Comparison of demographic and obstetric characteristics of Canadian primiparous women of advanced maternal age and younger age. J Obstet Gynaecol Can. 2011;33(8):820-9.

13. Juarez S, Revuelta-Eugercios BA, Ramiro-Farinas D, Viciana-Fernandez F. Maternal education and perinatal outcomes among Spanish women residing in southern Spain (2001-2011). Maternal and child health journal. 2014;18(8):1814-22.

14. Kassebaum NJ, Bertozzi-Villa A, Coggeshall MS, Shackelford KA, Steiner C, Heuton KR, et al. Global, regional, and national levels and causes of maternal mortality during 1990-2013: a systematic analysis for the Global Burden of Disease Study 2013. Lancet. 2014;384(9947):980-1004.

15. Blanc AK, Winfrey W, Ross J. New findings for maternal mortality age patterns: aggregated results for 38 countries. PloS one. 2013;8(4):e59864.

* 16. McCall SJ, Nair M, Knight M. Factors associated with maternal mortality at advanced maternal age: a population-based case-control study. BJOG. 2017;124(8):1225-33. Review of 105 maternal deaths in women aged $\geq 35$ years compared to deaths in women of younger age demonstrates that increased risk of maternal death is related to cigarette smoking, inadequate use of antenatal care, medical co-morbidities and previous pregnancy complications. The risk of maternal mortality was increased with multiple co-existing factors. 
* 17. Lean SC, Heazell AEP, Dilworth MR, Mills TA, Jones RL. Placental Dysfunction Underlies Increased Risk of Fetal Growth Restriction and Stillbirth in Advanced Maternal Age Women. Scientific reports. 2017;7(1):9677. Epub 2017/08/31. Basic scientific study demonstrating that placentas from women $\geq 35$ years of age have reduced plaecntal efficiency and altered placental structure and function. Similar changes are seen in a mouse model of advanced maternal age. This highlightes placental dysfunction as a potential mechanism underpinning adverse outcome in women $\geq 35$ years of age.

18. Vedmedovska N, Rezeberga D, Teibe U, Melderis I, Donders GG. Placental pathology in fetal growth restriction. Eur J Obstet Gynecol Reprod Biol. 2011;155(1):36-40.

19. Macdonald EM, Koval JJ, Natale R, Regnault T, Campbell MK. Population-based placental weight ratio distributions. Int J Pediatr. 2014;2014:291846.

20. Hayward $\mathrm{CE}$, Lean S, Sibley $\mathrm{CP}$, Jones RL, Wareing $\mathrm{M}$, Greenwood SL, et al. Placental Adaptation: What Can We Learn from Birthweight:Placental Weight Ratio? Front Physiol. 2016;7:28.

21. Jones CJ, Fox H. Syncytial knots and intervillous bridges in the human placenta: an ultrastructural study. J Anat. 1977;124(Pt 2):275-86.

22. Jones CJ, Fox H. Ultrastructure of the placenta in prolonged pregnancy. J Pathol. 1978;126(3):173-9.

23. Ptacek I, Smith A, Garrod A, Bullough S, Bradley N, Batra G, et al. Quantitative assessment of placental morphology may identify specific causes of stillbirth. BMC clinical pathology. 2016;16:1. Epub 2016/02/13.

24. Lean S, Stephens K, Heazell A, R.L. J. Matenral and Placental Inflammation and Oxidative Stress in Women of Advanced Maternal Age. Placenta. 2017;57(Suppl 1):229. 
25. Torres JI, Neves IA, Yariwake VY, Miglino MA, Veras MM. Avances maternal age and placental morphofunctional changes: An experimental study in mice. Placenta. 2017;51(Suppl 1):113.

26. Care AS, Bourque SL, Morton JS, Hjartarson EP, Davidge ST. Effect of advanced maternal age on pregnancy outcomes and vascular function in the rat. Hypertension. 2015;65(6):1324-30.

27. van der Heijden OW, Essers YP, Simkens LH, Teunissen QG, Peeters LL, De Mey JG, et al. Aging blunts remodeling of the uterine artery during murine pregnancy. Journal of the Society for Gynecologic Investigation. 2004;11(5):304-10.

28. Fretts RC, Duru UA. New indications for antepartum testing: making the case for antepartum surveillance or timed delivery for women of advanced maternal age. Seminars in perinatology. 2008;32(4):312-7.

29. Royal College Of Obstetricians and Gynaecologists. The Investigation And Management Of The Small-For-Gestational-Age Fetus. London: RCOG, 2013.

30. Walker KF, Bugg GJ, Macpherson M, Thornton J. Induction of labour at term for women over 35 years old: a survey of the views of women and obstetricians. Eur J Obstet Gynecol Reprod Biol. 2012;162(2):144-8.

31. Carolan M, Davey MA, Biro MA, Kealy M. Older maternal age and intervention in labor: a population-based study comparing older and younger first-time mothers in Victoria, Australia. Birth. $2011 ; 38(1): 24-9$

32. Smith GC, Cordeaux Y, White IR, Pasupathy D, Missfelder-Lobos H, Pell JP, et al. The effect of delaying childbirth on primary cesarean section rates. PLoS medicine. 2008;5(7):e144.

** 33. Walker KF, Bugg GJ, Macpherson M, McCormick C, Grace N, Wildsmith C, et al. Randomized Trial of Labor Induction in Women 35 Years of Age or Older. N Engl J Med. 2016;374(9):813-22. 
Randomized clinical trial to determine whether induction of labour at 39 weeks' gestation was associated with increased risk of Caesarean section. This study produced high-grade evidence that induction of labour did not increase Caesarean section and did not increase the risk of short-term neonatal or maternal outcomes. It was not large enough to determine whether induction of labour had an effect on perinatal mortality.

34. Walker KF, Dritsaki M, Bugg G, Macpherson M, McCormick C, Grace N, et al. Labour induction near term for women aged 35 or over: an economic evaluation. BJOG. 2017;124(6):929-34.

** 35. Knight HE, Cromwell DA, Gurol-Urganci I, Harron K, van der Meulen JH, Smith GCS. Perinatal mortality associated with induction of labour versus expectant management in nulliparous women aged 35 years or over: An English national cohort study. PLoS medicine. 2017;14(11):e1002425. This study used routinely collected data to demonstrate that induction of labour at 40 weeks of pregnancy in women aged 35 years or over was associated with a reduction in perinatal mortality before discharge from hospital and a reduction in meconium aspiration syndrome. There were small increases in Caesarean section and instrumental delivery in women who had an induction of labour.

\section{Figure Legends}

Figure 1 - Graph demonstrating the increase in the proportion of women $\geq 35$ giving birth in the UK from 1980 to 2016. Data obtained from Births by Parents' Characteristics 1938-2016, Office of National Statistics, London, 2018 (2).

Figure 2 - Graph of meta-regression of median maternal age against log Relative Risk of stillbirth demonstrating a correlation between maternal age and the risk of stillbirth $\left(R^{2}=0.61\right)$. Graph reproduced from Lean et al. PLoS ONE 12(10): e0186287. 
Figure 1

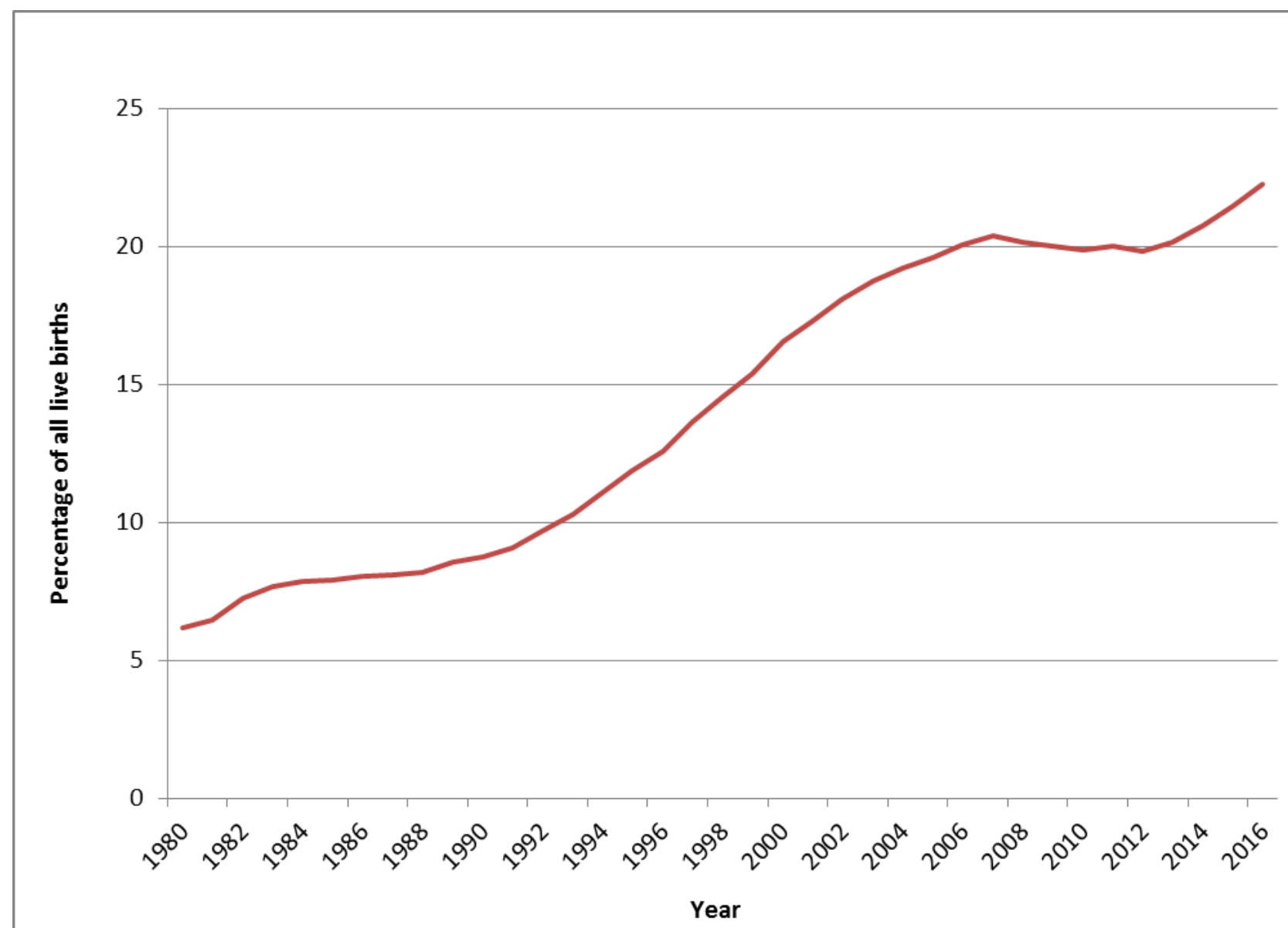


Figure 2

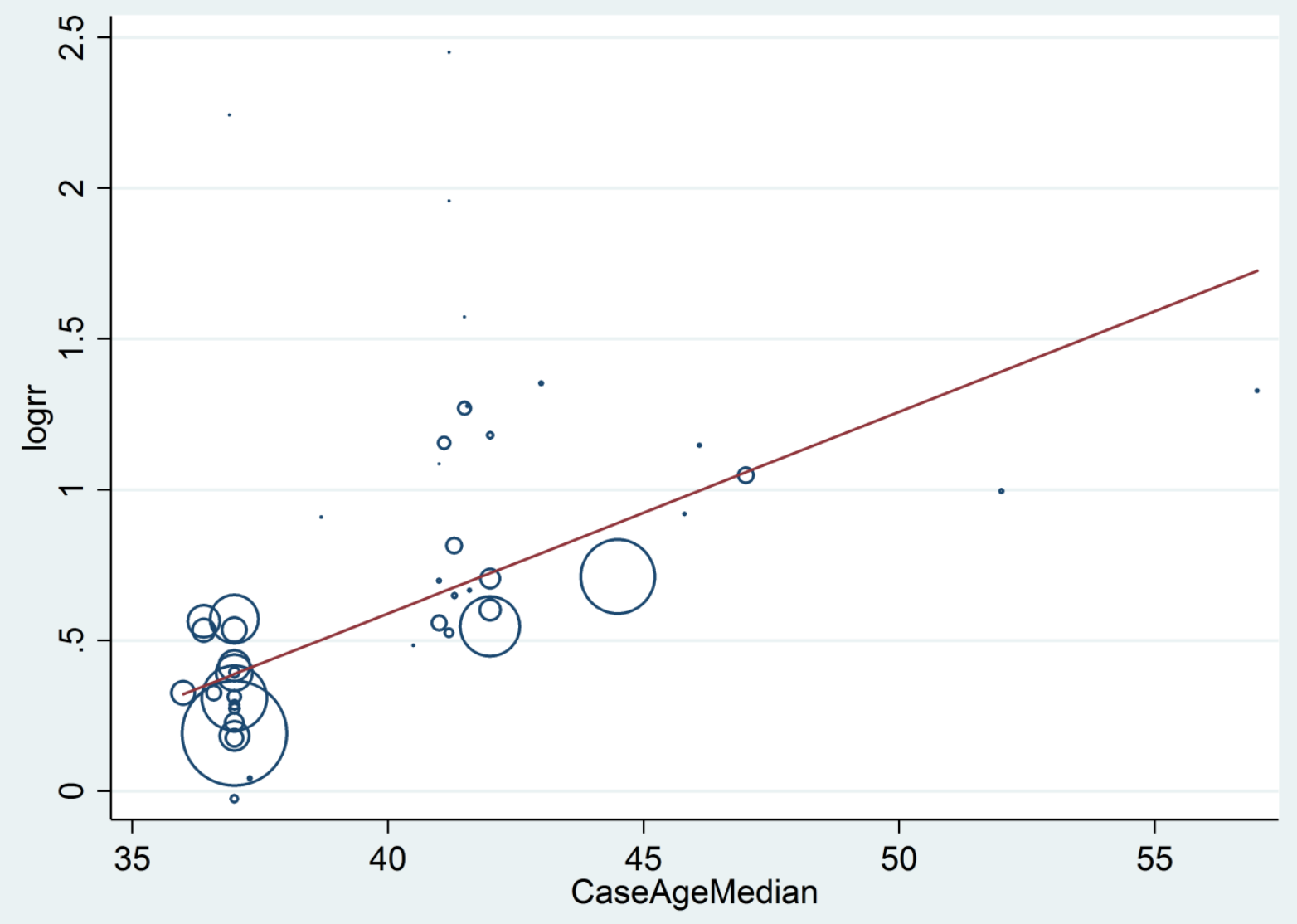

